\title{
Estimation of vehicular emissions and PM2.5 - A case study in Madurai city.
}

\author{
D Nancy Deborah ${ }^{1,3}$ and R Velkennedy ${ }^{2}$ \\ ${ }^{1}$ Research Scholar, Department of Civil Engineering, Thiagarajar College of Engineering, \\ Madurai - 625015, India. \\ ${ }^{2}$ Professor, Department of Civil Engineering, Thiagarajar College of Engineering, \\ Madurai - 625015, India. \\ ${ }^{3}$ Corresponding author. nancydeborah91@gmail.com
}

\begin{abstract}
Air quality monitoring, as important as it is, is impeded by a shortage of monitoring stations in nations like India. This research takes a different approach of monitoring and estimating automobile emissions. This is a case study that is only have been used in Madurai at this juncture. The use of a portable electro-chemical sensor at pre-determined stationary and mobile points and routes has been employed. Then after, the measurements were compared to the estimated emission values. The observations and experimental studies demonstrated that highspeed vehicle movement reduces particulate matter concentrations, and that reducing congestion could be one way to address the rising emissions crisis. One reason for the preference for airconditioned cars and fast-moving vehicles, even if it is a two-wheeler, is the average temperature. Ironically, this has resulted in an increase in vehicle emissions. Vehicle emissions were estimated, and 2.5-micron particulate matter was observed and discussed. The recommended strategy was discovered to be in agreement with the computed estimates. The proposed methodology for developing a database with minimal personnel and instrumental setup can reliably compensate the lack of data availability given the lack of monitoring stations.

Keywords: particulate matter, Madurai city, urban environment, Non-motorised transport, vehicular emissions
\end{abstract}

\section{Acknowledgement}

The authors would like acknowledge their host institution for Thiagarajar Research Fellowship.

\section{Introduction to Madurai city}

Madurai city is one of the oldest cities of South India with an inhabitation of 14,70,755 people [1]. The city is the functional headquarters of the district and is historically significant owing to its religious roots, longstanding heritage and the prosperity brought on by the River Vaigai. Madurai city is a pilgrim centre with several world-famous temples such as Meenakshi Amman temple, Skanda temple at Tirupparankundram[2], churches, mosques and palaces[3]. The city was home to several kings and has been the epicentre of the Tamil Sangam, Literature, Art and Culture[4]. The city was initially developed around the world-famous Meenakshi Amman Temple as shown in Figure 1. The temple is still serving as one of the hearts of the business districts for Madurai city housing, various businesses catering to home needs, tourism and even production. The city has been known for its small-scale and medium-scale industries right from its inception. Since its roots are religious, the city hosts a couple of major Hindu festivals like the Chitherai festival[5] which brings tourists and pilgrims from all over the state. Much of the original city plans revolved around the movement of people in and out of the temple and the palaces. With urbanization, the surrounding villages have now merged with the city that now spreads around 150 sq. $\mathrm{km}$ which is divided into 100 wards and four administrative zones. This historic city has faced has an 
exponential growth in population for about $9.6 \%$ in the last decade[6]. Though this has been facilitated with technological and employment opportunities, the rural population has rapidly moved to the urban areas of Madurai since 1990[6] bringing down the rural population, agricultural and farming land-use quite rapidly in the last couple of decades. This kind of urban sprawl has led to 'longer travel distances, higher fuel consumption, higher levels of vehicle ownership and usage[3]. A change in the urban sprawl pattern has also been observed as it has become more linear which used to be mono-centric in its initial stage as shown in Figure3.

\section{Research Significance}

For a city known for its city planning, Madurai has joined the league of congested urban cities which has had haphazard growth and decentralized planning. This can be contributed to the fast-paced urban sprawl happening in Madurai since the turn of 1990[3]. The urban sprawl and population boom bring into effect the increased vehicle usage and traffic congestion. However, the number of vehicles on road throughout the city has grown to an all-time high as with the busiest cities in India. Notwithstanding the development projects that are constantly happening, the inability to increase the capacity of roads and the fact that the business district in Madurai is divulged. The city experiences high temperatures that affect the urban population to resort to non-motorized transport.

\subsection{Liveability vs Air Pollution in Madurai city}

The imminent issue to be addressed amidst the Smart City revolution happening in India at the moment is the question of liveability and safety. Air pollution happens due to various reasons like industrial use, construction, burning of waste etc. [7] For the scope of this paper, the authors have restricted the study to vehicular emissions that are affecting the health of the urban public [8]. The urban air is affected by the presence of emission sources of gaseous pollutants and weather conditions such as the Atmospheric Boundary Layer (ABL) [9]. The predominant gaseous pollutants are carbon oxides, nitrogen oxides, sulfur oxides, hydrocarbons and particulate matter. The emissions due to transportation can be directly related to the quantities of gasoline and diesel consumption. The increase in emissions has been influenced by the increase in the number of motor vehicles and the increase in the distances these vehicles travel[7]. An increase in motor vehicle ownership has been observed at an average of 5\% per year in India since 1950 while the compounded growth rate of road length was 4.2\% [10]. The growth of vehicles has outpaced the growth of available road length which explains the overflowing roads that a city dweller experiences daily. This congestion leads to slow-moving vehicles which then indirectly leads to the concentration of pollutants at congested places [7], [11]. The pollutants have damaging health risks which may even be fatal or disabling for a lifetime when exposed to for a longer period. Prolonged consistent exposure to fine particulate matter causes irreversible damage to the respiratory and cardiovascular systems [12]. The probability of dying from non-communicable diseases (NCD) between the ages of 30 and 70, also known as premature mortality, was 23.3 in 2015 and has almost remained the same since then. Four main NCDs are cardiovascular diseases, cancer, chronic respiratory diseases and diabetes[13]. Fine particulate matter and physical inactivity are attributed as causes for cardiovascular diseases and chronic respiratory diseases[14][15]. Globally, about 4.2 million deaths are caused by polluted outdoor air which is about 2.5 times the standards set by WHO[16]. The general trend of using motor vehicles for even the shortest trips has led to obesity among 2 in every 5 children and adolescents aged 5-19 [16] witnessing a rise in prevalence from $0.5 \%$ to $2 \%$ in the last two decades.

The PM2.5 particles do not stop at respiratory and cardiovascular illnesses, but also the reproductive endocrine system. The fine, inhalable particles are now known to disrupt hormonal activity which is solely responsible for painful cramps and endometriosis[17]. This hormonal imbalance does not simply affect the present generation of women that are exposed to the abundance of particulate matter but the future generation as well.

\subsection{Research Statement}


Air pollution is a serious side-effect of urban sprawl. Identification of major contributor vehicles does shed light on the alternatives that could be sought. The lack of infrastructure for non-motorized transport and pedestrian movement within the city can be addressed to make a positive impact on the urban air quality. The widely known repartee to healthier living and hormonal imbalances is to move more. The movement through walking, cycling, etcetera proves good only if the user is healthy enough. Although that is not the case with many urban dwellers who cannot walk or cycle even as an exercise due to the high heat and particulate matter pollution. To realize a solution to this never-ending cycle, understanding of the problem areas has become necessary with urgency. Monitoring and measuring the pollution levels without hassle is crucial. The lack of monitoring stations and alternate methods from the pollution control board has led to a deficit in data availability.

Air pollution is a significant consequence of urban sprawl. The identification of primary contributor vehicles does give insight on potential alternatives. To have a positive impact on urban air quality, the city's lack of infrastructure for non-motorized transportation and pedestrian movement can be rectified. Moving more is a well-known remedy for better health and hormonal imbalances. Walking, cycling, and other forms of exercise are beneficial only if the user is in excellent health. Many urban dwellers, however, are unable to walk or cycle even as a form of exercise due to extreme heat and particulate matter pollution. Understanding the problem areas has become critical in order to find a solution to this neverending loop. It is necessary to easily monitor and measure pollution levels. The pollution control board's shortage of monitoring stations and other approaches has resulted in a data deficit.

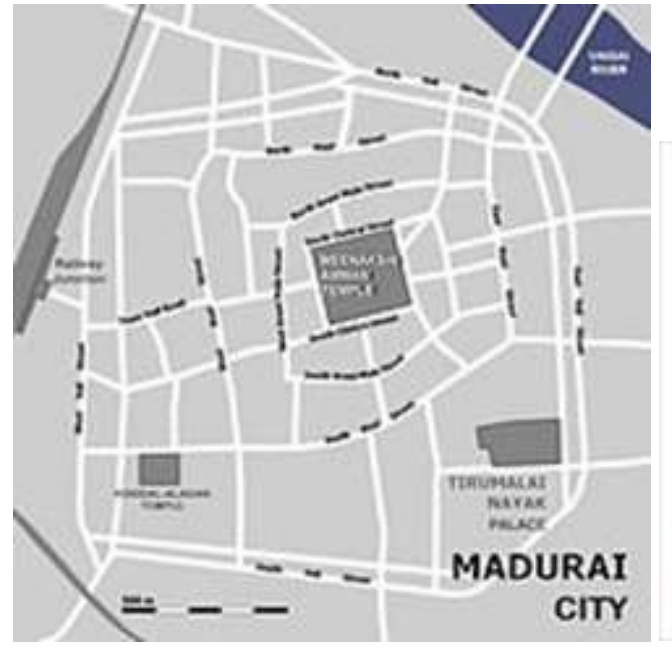

Figure1. Madurai city surrounding the Temple

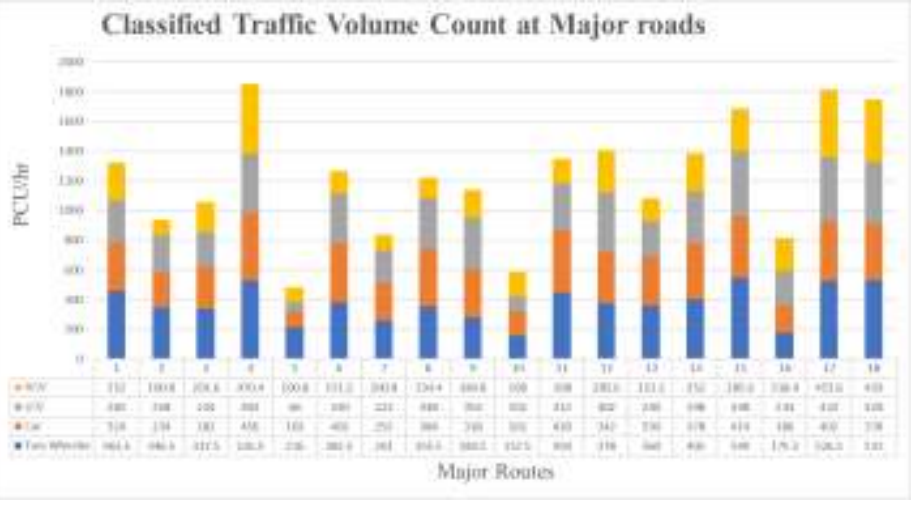

Figure 2. Classified Traffic Volume Count at Major roads 


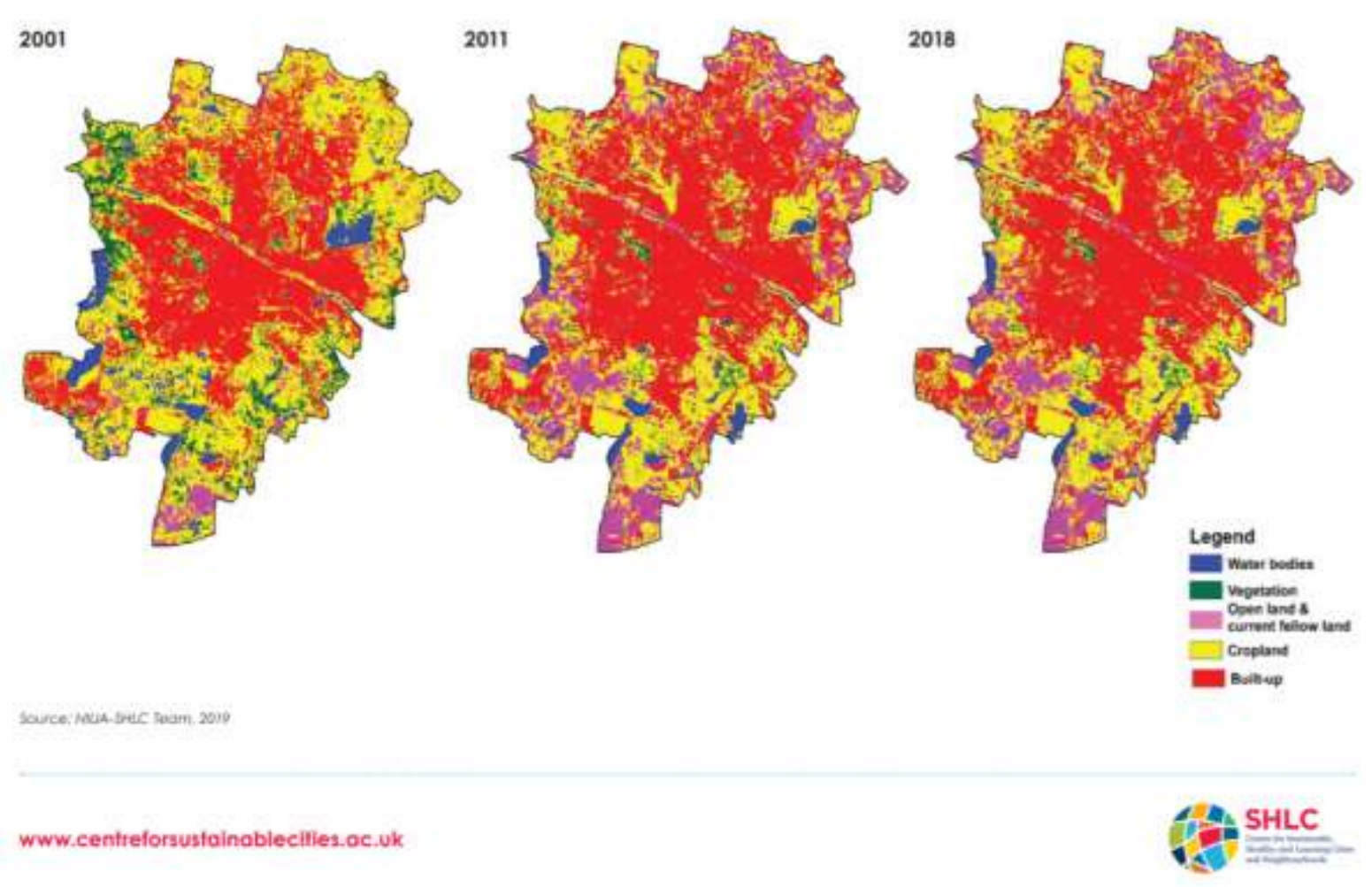

Figure 3. Madurai city growth of built-up urban sprawl area[18]

\section{Methodology}

This present study has identified the constituents of air pollution, the vehicle types, their emission factors and coefficients of fuel types used through the literature study. The traffic flow data of the major roads identified in Madurai city were assimilated and analyzed according to vehicle type as in Figure 2. The emissions for each vehicle type were estimated [11]. The estimates along the major roads are analyzed and discussed. The presence of particulate matter was investigated against the vehicle volume count during the observation period of 30 days using a portable electrochemical sensor as an experimental study. Observations during the day while in movement atop a vehicle and an average of three stationary points were made. Lack of monitoring stations and lack of funds for setting up observer stations by students and researchers has led to the need of innovative methods of observation. This study has employed a portable monitor that observes the particulate matter levels. Manual recording and tracking of locations, levels and assimilation is needed.

\section{Preliminary data collection.}

Madurai city is divided into four zones and 100 wards as administrative borders. The major roads were selected as per the guidelines from Madurai city corporation and are shown in Figure 4 along with the code names of the routes selected for reference. The traffic volume count is the highest around R4, R17 and R18 which lead to and fro from the Bus stands within the city. These areas also serve as business centres and hence the high footfall and vehicle movement during the day. 


\begin{tabular}{|c|c|c|c|c|c|c|c|c|c|c|c|c|c|}
\hline \multicolumn{14}{|c|}{ Climate date for Madurai, India (1981-2010) } \\
\hline Month & Jan & Feb & Mar & Apr & May & Jun & Jul & Aug & Sep & Oet & Nov & Dec & Year \\
\hline Record high " $\mathrm{C}$ ("F) & $\begin{array}{c}39.1 \\
(1024)\end{array}$ & $\frac{38.5}{(101,3)}$ & $\begin{array}{c}41.7 \\
\text { (107.1) }\end{array}$ & $\begin{array}{c}42.1 \\
(107.8)\end{array}$ & $\begin{array}{c}44.5 \\
(112.1)\end{array}$ & $\begin{array}{c}42.2 \\
(108.0)\end{array}$ & $\begin{array}{c}40.8 \\
(105.1)\end{array}$ & $\begin{array}{c}4000 \\
(104.0)\end{array}$ & $\begin{array}{c}398 \\
(103.6)\end{array}$ & $\begin{array}{c}40.0 \\
(104.0)\end{array}$ & $\begin{array}{c}38.0 \\
(100.4)\end{array}$ & $\begin{array}{l}35 . \overline{5} \\
(08.6)\end{array}$ & $\begin{array}{l}44.5 \\
(112.1)\end{array}$ \\
\hline Average high ${ }^{\circ} \mathrm{C}\left(\mathrm{C}^{\prime} \mathrm{F}\right)$ & $\begin{array}{l}30.8 \\
(87.4)\end{array}$ & $\begin{array}{l}33.3 \\
(91.9)\end{array}$ & $\begin{array}{c}36.0 \\
(968)\end{array}$ & $\begin{array}{l}372 \\
(90,0)\end{array}$ & $\begin{array}{c}37.9 \\
(1002)\end{array}$ & $\begin{array}{l}312 \\
(990)\end{array}$ & $\begin{array}{l}36.5 \\
(97.7)\end{array}$ & $\begin{array}{l}362 \\
(972)\end{array}$ & $\begin{array}{l}354 \\
\text { (95.2) }\end{array}$ & $\begin{array}{c}33.1 \\
(91.6)\end{array}$ & $\begin{array}{l}30.6 \\
\text { (ar:1) }\end{array}$ & $\begin{array}{l}30,0 \\
\{8 \in 0\}\end{array}$ & $\begin{array}{l}34.5 \\
(54,1)\end{array}$ \\
\hline Average low ${ }^{\circ} \mathrm{C}\left({ }^{\circ} \mathrm{F}\right)$ & $\begin{array}{c}19.6 \\
(67.3)\end{array}$ & $\begin{array}{l}21.5 \\
(70.7)\end{array}$ & $\begin{array}{c}23.4 \\
(74.1)\end{array}$ & $\begin{array}{l}256 \\
(78-1)\end{array}$ & $\begin{array}{l}26.3 \\
(79.3)\end{array}$ & $\begin{array}{c}26.2 \\
(70.2)\end{array}$ & $\begin{array}{l}25.9 \\
(78.6)\end{array}$ & $\begin{array}{l}25.5 \\
(77.9)\end{array}$ & $\begin{array}{l}24.6 \\
(76.3)\end{array}$ & $\begin{array}{l}23.7 \\
(74.7)\end{array}$ & $\begin{array}{l}22.7 \\
(72.9)\end{array}$ & $\begin{array}{l}21.3 \\
(70.3)\end{array}$ & $\begin{array}{l}23.9 \\
(75.0)\end{array}$ \\
\hline Record low 'C ('F) & $\begin{array}{c}15.6 \\
(60.1)\end{array}$ & $\begin{array}{c}10.5 \\
(50.9)\end{array}$ & $\begin{array}{c}16.9 \\
(62.4)\end{array}$ & $\begin{array}{c}19.4 \\
(66.9)\end{array}$ & $\begin{array}{c}17.8 \\
(84.0)\end{array}$ & $\begin{array}{l}17.8 \\
(64.0)\end{array}$ & $\begin{array}{c}19.4 \\
(68.9)\end{array}$ & $\begin{array}{l}20,6 \\
(69.1)\end{array}$ & $\begin{array}{c}18.5 \\
(65.3)\end{array}$ & $\begin{array}{c}18.9 \\
(66.0)\end{array}$ & $\begin{array}{c}17.2 \\
(63.0)\end{array}$ & $\begin{array}{c}16.7 \\
(62.1)\end{array}$ & $\begin{array}{c}10.5 \\
(50.9)\end{array}$ \\
\hline Average precipitation $\mathrm{mm}$ (inches) & $\begin{array}{c}8.5 \\
(0.33)\end{array}$ & $\begin{array}{c}11.0 \\
(0,43)\end{array}$ & $\begin{array}{c}18.3 \\
(0.72)\end{array}$ & $\begin{array}{c}60.1 \\
(2.37)\end{array}$ & $\begin{array}{c}80.6 \\
(3.17)\end{array}$ & $\begin{array}{l}34.3 \\
(1.35)\end{array}$ & $\begin{array}{c}56.9 \\
(2.24)\end{array}$ & $\begin{array}{l}93.9 \\
(3.70)\end{array}$ & $\begin{array}{l}121.5 \\
(4,78)\end{array}$ & $\begin{array}{l}185.8 \\
(7.34)\end{array}$ & $\begin{array}{l}147.2 \\
(5.80)\end{array}$ & $\begin{array}{c}51.3 \\
(2,02)\end{array}$ & $\begin{array}{r}869.4 \\
(34.23)\end{array}$ \\
\hline Average precipitation days & 0.8 & 1.1 & 1.2 & 3.3 & 4.0 & 2.2 & 2.9 & 4.6 & 6.8 & 9.7 & 6.8 & 3.4 & 46.6 \\
\hline \multicolumn{14}{|c|}{ Source: Indian Moteorological Departmont Mean data from 1981-2010 } \\
\hline
\end{tabular}

Figure 4. Average Temperature in Madurai city

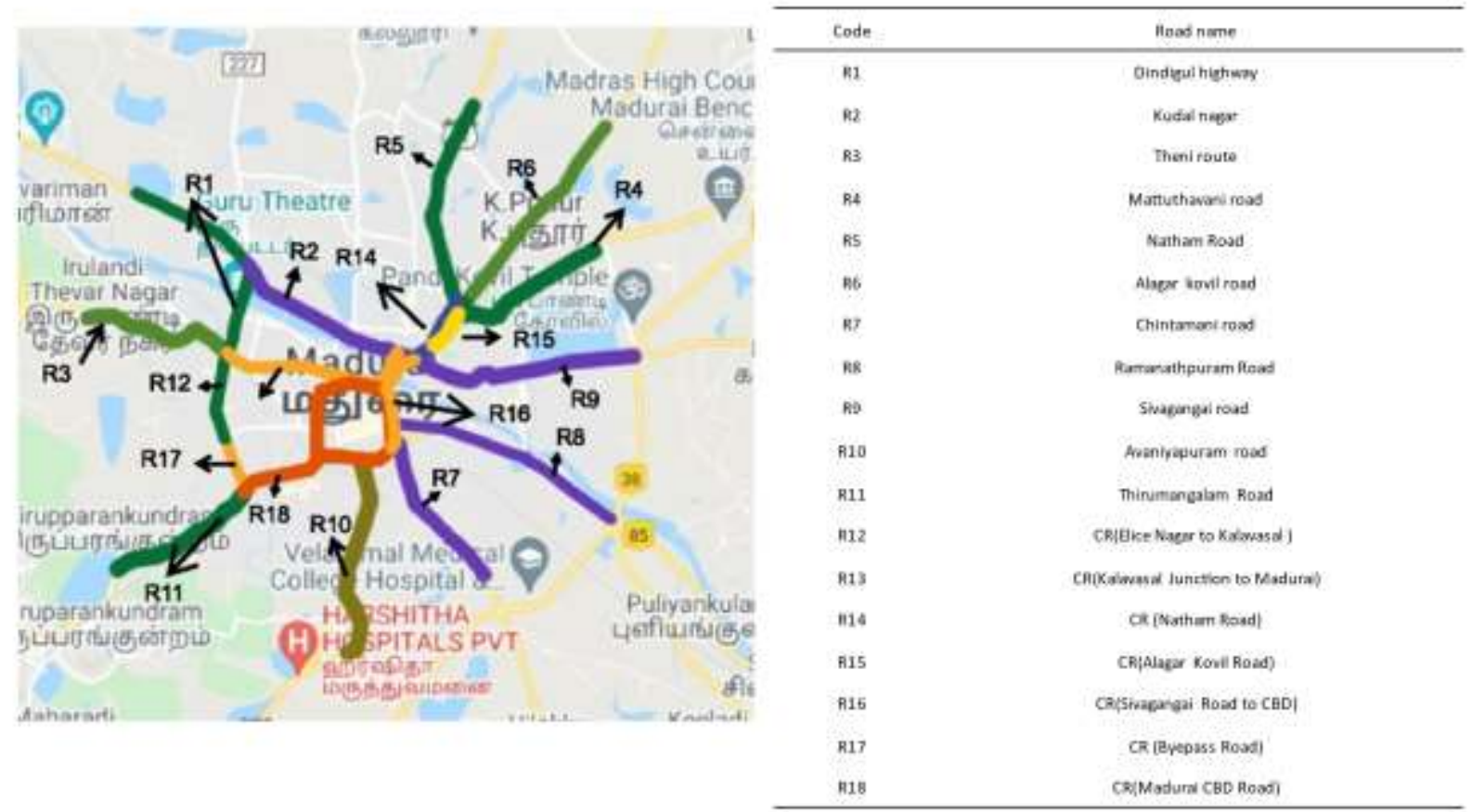

Figure 5. The selected routes and their codes

\section{Estimation of Emissions}

The emission of vehicle type was estimated by multiplying the number of vehicles of that vehicle type, $\mathrm{V}$ with $\mathrm{D}$, their distance travelled in a year in kilometres and e, the emission factor for the pollutant under consideration, $\mathrm{E}=(\mathrm{V} * \mathrm{D}) * \mathrm{e}$. The emission estimated is derived in $\mathrm{g} / \mathrm{km}$ [11]. For the scope of this study, the estimation of emission for two-wheelers, Cars, Buses and HCV are calculated. The emission factor is calculated for every vehicle type based on factors such as fuel consumption, average fuel efficiency, upload factor, driving power etc. [7] . For two-wheelers, the emission factor is derived by the average fuel efficiency over the fuel emission factor. Although the Indian scenario has different varieties of two-wheelers based on engine capacity, the reported fuel efficiency value is taken as 44.5 KMPL [19]. Similarly, emission factors for buses and HCV are calculated. Vehicular pollution also takes into account the presence of particulate matter.

\subsection{Observations from emission estimates}

Table 1 presents the emission factors taken into consideration for the calculation of emissions. When charted, the carbon dioxide emissions due to the movement of buses is found higher than the two-wheeler 
emissions, especially along R18 which is the central business district of Madurai around the worldfamous Meenakshi Amman temple. This area is one of the most crowded places in the city as it doubles as a pilgrim centre, a heritage site, a business hub and a marketplace for the locals. There are schools, churches, entertainment theatres, government offices and a bus stand. The presence of the Bus stand might single-handedly explain the high emission levels but with the recent Smart city mission, the Periyar Bus stand is getting a whole new makeover. This Smart City project includes a unified Periyar Bus stand with a roundabout-like structure that allows seamless transport. The parking and walkable features aim to bring about a complete walkable centre around the Meenakshi Amman Temple which is just beside the Bus stand.

Table 1. Emission factors of vehicle types for gaseous pollutants

\begin{tabular}{llllll}
\hline Pollutants & Two-wheeler & Cars, Jeeps & Bus & Trucks, lorries & Reference \\
\hline $\mathrm{CO}_{2}$ & 26.6 & 223.6 & 515.2 & 515.2 & {$[20][21]$} \\
$\mathrm{CO}$ & 2.2 & 1.98 & 3.6 & 3.6 & {$[20]$} \\
$\mathrm{CH}_{4}$ & 0.18 & 0.17 & 0.09 & 0.09 & {$[22][23]$} \\
$\mathrm{SO}_{2}$ & 0.013 & 0.053 & 1.42 & 0.28 & {$[7],[11]$} \\
$\mathrm{NO}_{\mathrm{x}}$ & 0.19 & 0.2 & 12 & 6.3 & {$[19]$} \\
$\mathrm{PM}$ & 0.05 & 0.03 & 0.56 & 0.28 & {$[11]$} \\
$\mathrm{HC}$ & 1.42 & 0.25 & 0.87 & 0.87 & {$[11]$} \\
\hline
\end{tabular}

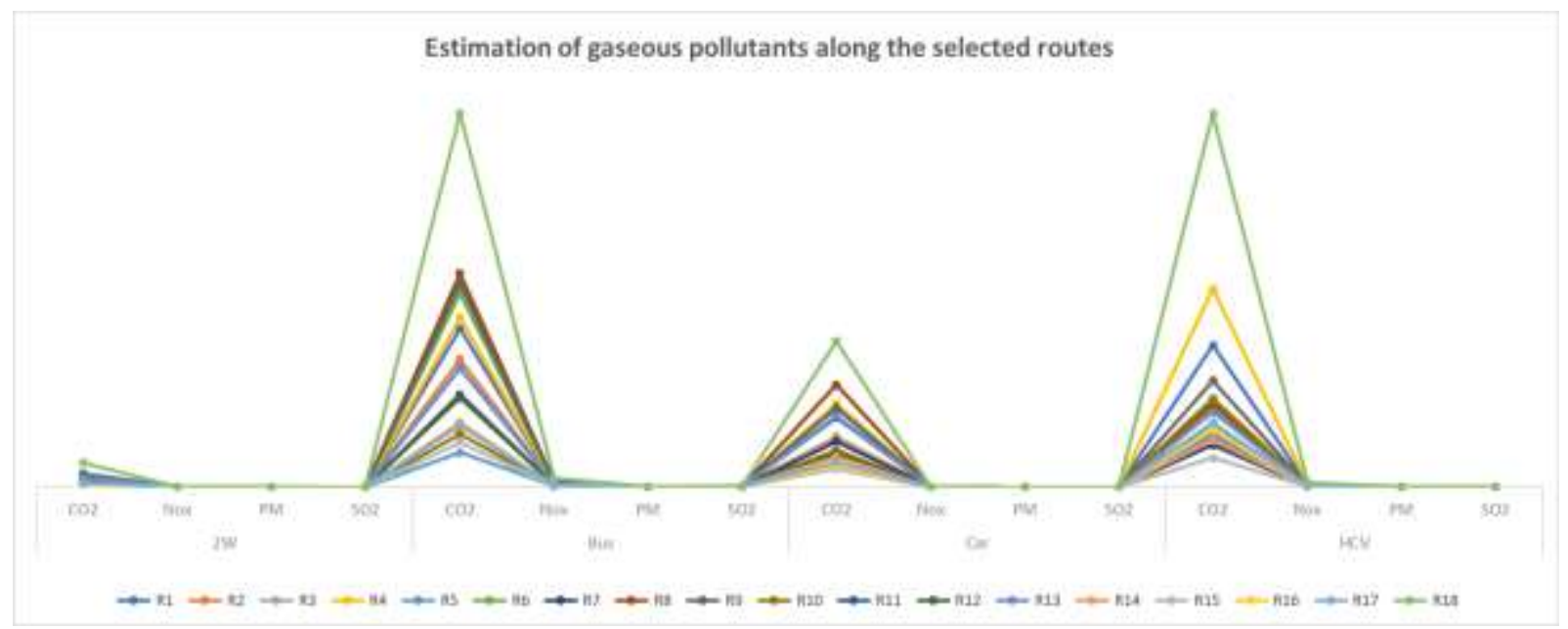

Figure 6. Estimated emissions on the selected routes

The Smart City project that is currently being implemented has a multi-level parking system [24] that aims to reduce the congestion and movement of vehicles that would need to enter the Central Business District. This will ensure free flow of public transport which is otherwise majorly blocked by the extensive parking on the narrow roads surrounding the Temple. A city of 14.5 lakh population services a floating population of 202 lakhs during peak tourist seasons[24]. The multi-level parking system as part of the combined Bus stand project is aimed to remove the on-street parking throughout the four iconic roads surrounding the Temple and to enable walkability around the temple which houses various kinds of businesses from textiles to jewellery and electronics. The reduction in slow-moving vehicles due to congested roads is expected to directly reduce the fine particle pollution in that area. Particulate matter of the size $2.5 \mu \mathrm{m}$ causes long term respiratory issues when found in higher concentrations[12]. PM2.5 is the fifth largest mortality factor listed for the year 2015 and is responsible for the negative environmental, atmospheric and climatic impacts such as fog, degradation of visibility etc.[25]. The PM2.5 concentration is considered hazardous than Suspended Particle Matter (SPM) or Particulate Matter 10(PM10) due to its smaller size. 


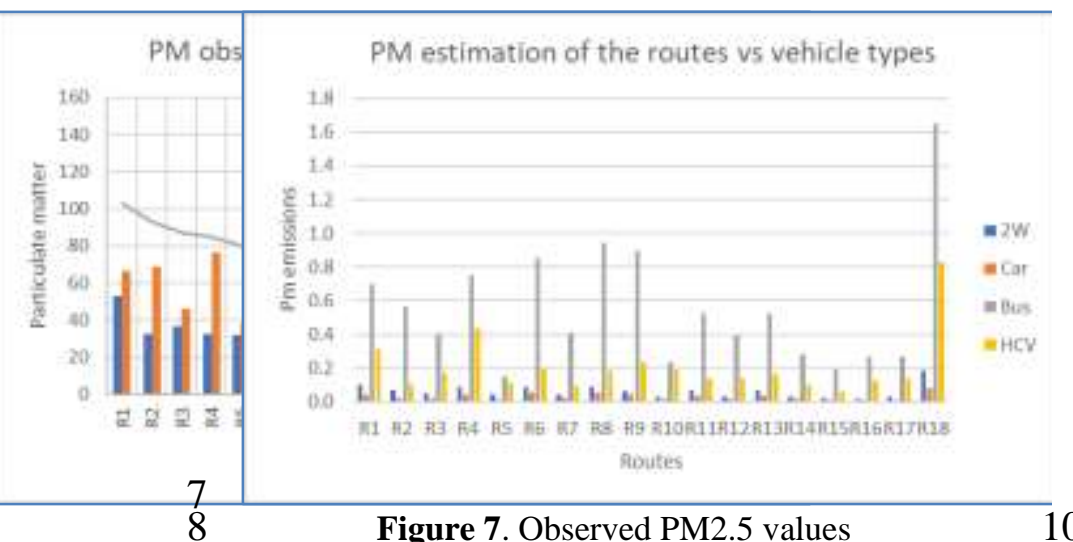

9
Figure 8. Estimated PM2.5 values
11

\section{Summary and Observations}

The selected routes throughout Madurai city focused around the central business district and its connecting roads. Madurai city was built in the $3^{\text {rd }}$ century around the Meenakshi Amman Temple and the city survived the surrounding villages until the turn of 1900. Since then, Madurai city has faced an unprecedented sprawl that with further planning and development such as shifting corporation offices, parks and complexes, the urban sprawl has turned linear. The linear sprawl, though planned partially, has its demerits given environmental and mobility patterns. The linear urban sprawl has increased the travel distances and hence the vehicular emissions. The emissions from the vehicular movement were estimated and particulate matter pollution was observed to be compared against the vehicular population during the observation period. The results were tabulated and charted to enable a better understanding of the levels. The levels prescribed by the Central Pollution Control Board are higher than the WHO threshold [26] [15].

\subsection{Comparison between estimated and recorded particulate matter levels}

The methodology carried out in this study to estimate and analyze the particulate matter along street level has not been experimented on before. The conventional method of gathering data with an air quality monitor is the only way through which data has been collected and analyzed. Although this seems to be the most accurate particulate matter data collection method, this is seldom feasible for developing cities as it requires infrastructure and resources that resarchers of developing countries like India are often stunted with. This study has been based on the methodology that would simplify the process of data estimation to analyze the changing trends of particulate matter concentration and other gaseous pollutants that are harmful for the urban population. It might just be too late before any recoverable remedies are put into place owing to the slow-killing process of particulate matter concentrations. Long term respiratory issues causes the nation to face an increase in the quality-adjusted life years (QALY). A person who could live healthily for ten years without the need for medical intervention is deemed to have lost 5 years when that person is burdened with illness leading upto his death within the $8^{\text {th }}$ year. Although the calculation of QALY is out of scope of this study, the burden of disease that stunts the workforce is a serious issue and should be considered a threat to the economic development of the nation within a decade or two. The lack of data availability can be bridged with the proposed methodology as an alternative until detailed monitoring station is set up.

\subsection{Walkability and 15-min city}

Madurai city does not generally face any visibility challenge due to vehicular emissions. As with other developing urban centres, the city faces an increase in urban temperature due to urbanisation. The PM2.5 levels, although not as high as PM10 levels observed in the experimental study, it has many drastic effects than its counterpart even in lower concentrations. Madurai city faces summer during March-May but even 
the lowest average temperature recorded is in December at $25^{\circ} \mathrm{C}$. Particulate matter of the size 2.5 micrometers are by nature swept away in rain or by wind but the city's temperature average does not aid to that situation. In addition, the wind flow caused by the movement of vehicles does help in shifting the concentration of pollutant particles thus proving that solving the congestion issue on roads could inadvertently aid in the reduction of pollution. One other way to approach this solution is to minimise the number of vehicles on road. However further study is required in this area to understand the relation between the speed of vehicles and the concentration of particulate matter. Further studies focused on this relationship will bring solutions to the issue of growing vehicle ownership that is inevitable in the coming years. The city has seen an increase of $9.6 \%$ since 2001 as per the census handbook,2011 [6]. Learning from the example of the state capital, the district of Chennai which is growing at an average of $21 \%$ per decade since 2001[27], Madurai city needs to focus on the non-motorized transport facilities and walkability as it works toward growing into a smart city. The introduction of walkable spaces has already begun as part of the Smart City Missions in Madurai city. Being a heritage city, cycling paths have not been very feasible within the central city area. As part of making Madurai city smart, Non-Motorized Transport is being given attention. Encouraging walkable spaces and cycling within the city is focused on[28]. However as seen in Figure 3, the temperature is hardly manageable and this proves to be a bigger hindrance for the people to choose NMT. Further studies on shaded cycle paths and interesting walkways can influence more young people to take to non-motorized transport. The emerging concepts of $15-$ minutes city and skateboarding even across town are catching up in the European continent. Incorporating such sustainable modes not only helps reduction of traffic and vehicular pollution but also aids to improve the average health statistic where childhood obesity is growing into an issue[29]. Further studies are required on enabling non-motorised transport for optimum and longer stretches possible within a city within an affordable budget. The effects on health since switching to a cycling or walking mode can also be studied.

\section{Conclusion}

Vehicular emissions are estimated exclusively on the basis of the availability of vehicular statistics for any Indian city. The monitoring equipment is both inexpensive and readily available. Although the proposed method does not eliminate the necessity for traditional air quality monitoring stations, it does provide an effective and feasible monitoring and data collection system that will benefit future study. The strategy used in this study is straightforward, inexpensive, and entirely feasible with a group of 6-10 people. This strategy could be tested in other cities as well. This study is a first in simplifying the data collection process, which has been a great difficulty for the author. This study focuses on the use of trend analysis of emissions rather than a comprehensive data harvesting strategy that requires the establishment and operation of standard monitoring stations.

Data availability statement: All data generated during this study are included in this article in tabular or graphical form.

Conflict of Interest: The authors declare that they have no conflict of interest.

\section{References}

[1] Ministry of Urban Development Government of India, "Class I cities census data," vol. 43, no. 11. pp. 931-937, 2004.

[2] C. Branfoot, "The Madurai Nayakas and the Skanda temple at Tirupparankundram," Ars Orientalis, vol. 33. pp. 147-180, 2003, doi: 10.2307/4434276.

[3] P. Saravanan and P. Ilangovan, "Identification of Urban Sprawl Pattern for Madurai Region Using GIS," Int. J. Geomatics Geosci., vol. 1, no. 2, 2010.

[4] S. Sm, K. Chandrabose, U. Umamaheshwari, and T. Maharajan, "Feasibility Study Of Metro Transport: Case Study Madurai," Int. J. Civ. Eng. Technol., vol. 4, no. 4, pp. 976-6308, 2013.

[5] D. H. Stanley, M. R. Binford, M. Camerini, and J. W. Elder, "Wedding of the Goddess," J. Am. 
100

101

102

103

104

105

106

107

108

109

110

111

112

113

114

115

116

117

118

119

120

121

122

123

124

125

126

127

128

129

130

131

132

133

134

135

136

137

138

139

140

141

142

143

144

145

146

147

148

149

150

Folk., vol. 92, no. 365, 1979, doi: 10.2307/539437.

[6] Census, "District CENSUS Handbook 2011," 2011.

[7] T. V. Ramachandra, B. H. Aithal, and K. Sreejith, "GHG footprint of major cities in India," Renew. Sustain. Energy Rev., vol. 44, pp. 473-495, 2015, doi: 10.1016/j.rser.2014.12.036.

[8] S. Host, E. Chatignoux, C. Leal, and I. Grémy, "Health risk assessment of traffic-related air pollution near busy roads," Rev. Epidemiol. Sante Publique, vol. 60, no. 4, pp. 321-330, 2012, doi: 10.1016/j.respe.2012.02.007.

[9] L. Zhou, X. Xu, G. Ding, M. Zhou, and X. Cheng, "Diurnal variations of air pollution and atmospheric boundary layer structure in Beijing during winter 2000/2001," Adv. Atmos. Sci., vol. 22, no. 1, pp. 126-132, 2005, doi: 10.1007/bf02930876.

[10] MORTH, "Basic_Road_Statics_of_India.pdf." 2019, [Online]. Available: https://morth.nic.in/basic-road-statistics-india.

[11] T. V. Ramachandra and Shwetmala, "Emissions from India's transport sector: Statewise synthesis," Atmos. Environ., vol. 43, no. 34, pp. 5510-5517, 2009, doi: 10.1016/j.atmosenv.2009.07.015.

[12] T. Li et al., "Fine particulate matter (PM2.5): The culprit for chronic lung diseases in China," Chronic Dis. Transl. Med., vol. 4, no. 3, pp. 176-186, 2018, doi: 10.1016/j.cdtm.2018.07.002.

[13] World health statistics 2020. 2020.

[14] I. S. Kim et al., "Long-term fine particulate matter exposure and cardiovascular mortality in the general population: a nationwide cohort study," J. Cardiol., vol. 75, no. 5, pp. 549-558, 2020, doi: 10.1016/j.jjcc.2019.11.004.

[15] J. Rovira, J. L. Domingo, and M. Schuhmacher, "Air quality, health impacts and burden of disease due to air pollution (PM10, PM2.5, NO2 and O3): Application of AirQ+ model to the Camp de Tarragona County (Catalonia, Spain)," Sci. Total Environ., vol. 703, no. xxxx, p. 135538, 2020, doi: 10.1016/j.scitotenv.2019.135538.

[16] World health statistics 2018. 2018.

[17] World health statistics 2019. 2019.

[18] D. Kundu, P. Sharma, B. Lahiri, and C. Sangtani, "Madurai : a shrinking and segregated city," 2020.

[19] C. Gajjar and A. Sheikh, "India Specific Road Transport Emission Factors," 2015.

[20] S. Baidya and J. Borken-Kleefeld, "Atmospheric emissions from road transportation in India," Energy Policy, vol. 37, no. 10, pp. 3812-3822, 2009, doi: 10.1016/j.enpol.2009.07.010.

[21] J. Pucher, Z. R. Peng, N. Mittal, Y. Zhu, and N. Korattyswaroopam, "Urban transport trends and policies in China and India: Impacts of rapid economic growth," Transp. Rev., vol. 27, no. 4, pp. 379-410, 2007, doi: 10.1080/01441640601089988.

[22] E. Arsenio, K. Martens, and F. Di Ciommo, "Sustainable urban mobility plans: Bridging climate change and equity targets?," Res. Transp. Econ., 2016, doi: 10.1016/j.retrec.2016.04.008.

[23] N. Ole Kenneth, "EMEP/EEA air pollutant emission inventory guidebook 2013: Technical guidance to prepare national emission inventories," 2019. [Online]. Available: http://www.eea.europa.eu/publications/emep-eea-guidebook-2013.

[24] Ahmedabad Municipal Corporation, "The Smart City Challenge Stage 2 Smart City Proposal Madurai," Gov. India, no. 7, p. 113, 2016.

[25] V. Sreekanth, B. Mahesh, and K. Niranjan, "Gradients in PM2.5 over India: Five city study," Urban Clim., vol. 25, no. January, pp. 99-108, 2018, doi: 10.1016/j.uclim.2018.06.001.

[26] CPCB, "Guidelines for the Measurement of Ambient Air Pollutants (NAAQS)," Cent. Pollut. Control Board, Gov. India, 2009, [Online]. Available: http://www.cpcb.nic.in.

[27] S. P. Sekar and S. Kanchanamala, "An Analysis of Growth Dynamics in Chennai Metropolitan Area," Inst. T. Planners, India, vol. 8, no. 4, pp. 31-57, 2011.

[28] J. Shah, "Preparation of SMART CITY PLAN \& PROPOSAL," pp. 1-23, 2015.

[29] V.-Y. L'IV Com Sàrl, "World Health Statistics 2017," World Heal. Organ. Press, vol. 5, no. 1023, pp. 1-24, 2017. 